\title{
Revus
}

Journal for Constitutional Theory and Philosophy of

Law / Revija za ustavno teorijo in filozofijo prava

36 | 2018

Revus (2018) 36

\section{Diez observaciones y un cuadro final sobre permisos y normas permisivas}

A propósito de un aspecto de la teoría del derecho de Eugenio Bulygin Ten observations and a final frame on permissions and permissive norms

\section{Juan Ruiz Manero}

\section{(2) OpenEdition}

\section{Journals}

Edición electrónica

URL: http://journals.openedition.org/revus/3728

DOI: $10.4000 /$ revus.3728

ISSN: $1855-7112$

Editor

Klub Revus

\section{Edición impresa}

Fecha de publicación: 10 diciembre 2018

ISSN: 1581-7652

\section{Referencia electrónica}

Juan Ruiz Manero, "Diez observaciones y un cuadro final sobre permisos y normas permisivas », Revus [Online], 36 | 2018, Online since 23 February 2017, connection on 30 April 2019. URL : http:// journals.openedition.org/revus/3728; DOI : 10.4000/revus.3728

Este documento fue generado automáticamente el 1 mayo 2019.

All rights reserved 


\section{Diez observaciones y un cuadro final sobre permisos y normas permisivas}

A propósito de un aspecto de la teoría del derecho de Eugenio Bulygin

Ten observations and a final frame on permissions and permissive norms

Juan Ruiz Manero

\section{Introducción}

(1) Los permisos y las normas permisivas son uno de los problemas de teoría del derecho de los que Eugenio Bulygin ha venido ocupándose una y otra vez. ${ }^{1}$ En sus escritos, la distinción capital a este respecto es la que media entre el concepto prescriptivo de permisión y dos conceptos descriptivos de permisión: el de permiso fuerte y el de permiso débil. El concepto prescriptivo de permisión es el expresado por el término "permitido»

cuando este figura en una norma. Cuando el término «permitido» figura en una proposición normativa, cuando se dice, por ejemplo, que una cierta acción $p$ está permitida en un cierto caso en un cierto sistema de normas, el término «permitido» es usado descriptivamente y es, en este uso, ambiguo: pues puede significar bien que forma parte de ese sistema una norma que permite $p$ en ese caso, o bien que no forma parte de ese sistema una norma que prohíba $p$ en ese mismo caso. En el primer caso se trata del concepto descriptivo fuerte de permisión y, en el segundo, del concepto descriptivo débil de permisión. Pues bien: Carlos Alchourrón y Eugenio Bulygin han venido sosteniendo,

desde Normative Systems (1971), que estas distinciones hacen

posible solucionar el problema de la interdefinibilidad de «permitido» $y$ «prohibido», clarificar la naturaleza de los principios de permisión y de prohibición y eliminar parte de los prejuicios corrientes respecto de las «lagunas» en los sistemas normativos. (Alchourrón \& Bulygin 1991a: 216)

En estas notas me propongo centralmente dos cosas: mostrar, primero, que, aunque la distinción entre permisos fuertes y débiles es una distinción útil y clarificadora, no tiene, sin embargo, en relación con algún extremo importante, el alcance que Bulygin le atribuye; segundo, que la distinción entre permisos fuertes y débiles debe, para ser ella 
misma enteramente fructífera, ser complementada con otras dos distinciones: la que media entre permisos protegidos y no protegidos y la que media entre permisos concluyentes y permisos prima facie. ${ }^{2}$

\section{Permisos fuertes y permisos débiles: una crítica parcial}

(2) Desde el punto de vista de la acción a que se refiere el permiso, la existencia de norma permisiva y la ausencia de norma prohibitiva son situaciones equivalentes: en uno y otro caso, la acción se encuentra, desde el punto de vista del sistema normativo de referencia, disponible para el sujeto. Tanto en el caso del permiso fuerte como en el del permiso débil, la realización de la acción supone que no se ha violado ninguna norma del sistema. ${ }^{3}$

(3) Ello es lo que explica que un sistema compuesto exclusivamente de normas permisivas sería funcionalmente inútil para guiar la conducta. La situación del sujeto frente a tal sistema sería exactamente la misma de aquella en la que se encontraría en ausencia de cualquier sistema normativo. Esto, me parece, es lo que muestra con claridad y gracia el relato que Echave, Urquijo y Guibourg hicieran de la situación de la imaginaria tribu de los charrúas tras las primeras disposiciones (exclusivamente permisivas) dictadas por el

imaginario Toro Sentado. ${ }^{4}$

(4) El dictado de disposiciones permisivas sólo tiene sentido en determinados contextos y para determinadas finalidades; contextos que suponen, todos ellos, un trasfondo de prohibiciones. En un libro publicado conjuntamente con Manuel Atienza hace ya casi veinte años, identificábamos así estas finalidades: ${ }^{5}$ a) Cancelar una prohibición previamente existente. En este caso, el dictado de una disposición permisiva equivale al dictado de una disposición derogatoria; b) Exceptuar una prohibición. En tal caso, el dictado de una disposición permisiva equivale al dictado de una disposición que exceptuara la prohibición de que se trate; c) Aclarar que un cierto caso no está comprendido en el alcance de una prohibición. En este supuesto, el dictado de una disposición permisiva equivale al dictado de una disposición definitoria (cuanto menos parcial) de la conducta cubierta por aquélla; d) Introducir indirectamente una prohibición

(de prohibir, de impedir o de sancionar) a las autoridades subordinadas. En tal caso, el dictado de una disposición permisiva equivale al dictado de una regla prohibitiva (de prohibir, impedir o sancionar) a las autoridades subordinadas. De forma que la relevancia de las disposiciones permisivas parece poder explicarse enteramente en términos de reglas prohibitivas, de derogación o excepción de las mismas y de definiciones. 


\section{Permisos protegidos y permisos no protegidos}

(5) Como se ha dicho arriba en (2), en relación con la acción a que se refiere el permiso, la existencia de norma permisiva y la ausencia de norma prohibitiva son situaciones equivalentes. Ello no obstante, la existencia de norma permisiva puede marcar una diferencia con la inexistencia de norma en relación con una cierta clase de acciones relacionadas con la acción permitida, dado un contexto de jerarquía de autoridades. Si una autoridad de grado superior permite prescriptivamente una cierta acción en un cierto caso genérico ello implica la prohibición a las autoridades subordinadas a ella de interferir, prohibiendo, impidiendo o sancionando dicha acción en dicho caso genérico o en casos menos genéricos o individuales comprendidos en aquél. ${ }^{6}$ De esta forma, el permiso fuerte dictado por una autoridad de grado superior implica que ese permiso resulta protegido frente al uso por parte de autoridades normativas de grado inferior de sus poderes normativos.

(6) Ello no obstante, las acciones que pueden interferir con la permitida no se circunscriben a las que puedan llevar a cabo autoridades subordinadas mediante el uso de sus poderes normativos. Otros muchos sujetos pueden realizar acciones que interfieran

con la acción permitida (no importa que esta permisión sea débil o fuerte) y estas acciones de interferencia están, siempre que no se lleven a cabo por medio de la fuerza

física, permitidas a no ser que haya una norma que las prohíba. De ahí que, a este respecto, la distinción importante no sea tanto la distinción entre permisos débiles y fuertes como la que media entre permisos no protegidos y permisos protegidos. Llamamos permisos no protegidos a aquellos que no van acompañados de una norma que prohíba la interferencia con la acción permitida por medios distintos de la fuerza física o

de una norma que obligue a facilitar, en algún sentido, la realización de la acción permitida. Permisos protegidos serían aquellos que van acompañados de alguna de tales normas que prohíben la interferencia o que obligan a la facilitación. 
(7) La distinción entre permisos débiles y fuertes y la distinción entre permisos no protegidos y permisos protegidos no son equivalentes. Todos los permisos débiles son,

desde luego, permisos no protegidos, pues la presencia de norma prohibitiva de la interferencia, o de norma que obligue a la facilitación implica una formulación indirecta del permiso, o sea, su carácter de permiso fuerte. Y, dada una jerarquía de autoridades, todos los permisos fuertes son permisos protegidos frente al uso de sus poderes normativos por parte de las autoridades subordinadas a aquella que concedió el permiso. Pero dentro de los permisos fuertes los hay tanto protegidos como no protegidos frente a acciones llevadas a cabo por sujetos distintos de las autoridades subordinadas ejerciendo sus poderes normativos: supongamos una norma que permita aparcar el coche dentro de cierta área, o sentarse en los bancos de un cierto parque. Aunque son permisos fuertes, se

trata de permisos no protegidos: pues ninguna norma prohíbe que otros me impidan hacer uso del permiso para aparcar mi coche, o para sentarme en el banco, simplemente ocupando antes los espacios de aparcamiento, o los asientos, disponibles. El permiso sería protegido si a la norma permisiva le acompañara otra norma que prohibiera a otros -que no tienen por qué ser todos los demás- interferir con el uso del permiso. Por ejemplo, los

espacios de aparcamiento reservados para los taxistas están protegidos frente a la interferencia que pudieran llevar a cabo los no taxistas aparcando en ellos, pero no están protegidos frente a la interferencia llevada a cabo de la misma manera por otros taxistas.

Hablando en general, diríamos que la categoría de los permisos no protegidos coincide con la de los privileges hohfeldianos: A tiene un permiso no protegido frente a B en relación con un acto $\mathrm{X}$ cuando simplemente $\mathrm{B}$ no tiene derecho a exigirle a A que realice $\mathrm{X}$ o se abstenga de realizar X. La categoría de los permisos protegidos coincide, por su parte, con la de los claims de ejercicio facultativo: A tiene un permiso protegido frente a B en relación con un acto $\mathrm{X}$ cuando, si A lo decide así, B tiene el deber de realizar el acto $\mathrm{Y}$, facilitador de la realización de $\mathrm{X}$, o de abstenerse de realizar el acto $\mathrm{Y}$, que interfiere con

\section{Permisos concluyentes y permisos prima facie}

(8) Junto con la distinción entre permisos protegidos y permisos no protegidos es preciso introducir una ulterior distinción en materia de permisos, la que media entre permisos prima facie y permisos concluyentes. Los permisos prima facie están contenidos en normas jurídicas predispuestas, que pueden ser bien principios, bien reglas derrotables, o en sus consecuencias lógicas. Los permisos concluyentes son los que encontramos en el nivel de

las calificaciones deónticas definitivas y, en consecuencia, en la regla que opera como premisa mayor del razonamiento que da solución a un caso. La distinción entre permisos prima facie y permisos concluyentes es, así, una distinción relativa al proceso del razonamiento aplicativo del derecho. Las distinciones entre permisos débiles y fuertes y entre permisos no protegidos y permisos protegidos son, ambas, por el contrario, relativas al sistema jurídico: la primera depende de que en el sistema, o bien meramente no esté presente una norma prohibitiva o bien esté presente una norma permisiva; la segunda, la distinción entre permisos protegidos y permisos no protegidos, depende, como se acaba de indicar, de que en el sistema esté presente o no una norma que estipule para personas distintas del titular del permiso bien la obligación de facilitar la conducta permitida, bien la prohibición de interferir con ella. 
(9) Una calificación deóntica definitiva permisiva puede resultar a partir de cinco situaciones de partida distintas. La primera de ellas es que el caso esté cubierto de entrada por una regla permisiva inderrotable, en cuyo caso la distinción entre permiso prima facie y permiso concluyente se esfuma: todo lo permitido por una regla así está concluyentemente permitido. Aunque últimamente parece constituir una moda la afirmación de que todas las reglas son derrotables, creo que las cosas no son de ningún modo así: ciertas reglas son, a mi juicio, entendidas por nuestras comunidades jurídicas como inderrotables: entre las reglas permisivas, y de manera muy destacada, es entendida como inderrotable la regla de clausura constituida por la exigencia de tipicidad penal, de acuerdo con la cual todo lo no prohibido de forma expresa en el ámbito penal está concluyentemente permitido en ese mismo ámbito. La segunda de las posibles situaciones de partida es que el caso se encuentre cubierto por una regla permisiva derrotable y quepa descartar la derrota de la regla porque no se da aquello que podría derrotarla, esto es, que su aplicación al caso resulte intolerablemente anómala desde el punto de vista valorativo, atendiendo al balance entre los principios involucrados. La tercera de estas situaciones de partida es que el caso no esté cubierto por ninguna regla pero el balance entre los principios relevantes no exija el surgimiento de una regla prohibitiva o de obligación. La cuarta situación es que al caso le resulte de entrada aplicable un principio permisivo y este principio no se vea desplazado por otro que, en relación con las propiedades del caso, tenga un mayor peso. La quinta de estas situaciones de partida es que el caso esté cubierto de entrada por una regla prohibitiva, pero esta regla se vea desplazada por una regla permisiva que venga exigida por el balance entre los principios relevantes del sistema: se trata de los supuestos de lo que se ha llamado licitud atíica, entre los que cabe distinguir tres clases: supuestos de fuera del alcance, de excepción o de 
(10) Los puntos cruciales y, al mismo tiempo, más débiles, del tratamiento de los problemas planteados por los permisos por parte de Eugenio Bulygin residen en una doble tesis: en primer lugar, en la asimilación de las situaciones de permiso débil, esto es, de ausencia de norma, a las situaciones de laguna normativa y, en segundo lugar, la consideración de que, en tales situaciones de laguna normativa, el derecho no proporciona ninguna guía para los órganos de aplicación sino que aboca a estos a decidir mediante un ejercicio de discreción irrestricta. En un caso de ausencia de norma, con tal de que el caso aparezca configurado integrando una propiedad relevante para el derecho

(y esto equivale a que esté presente una propiedad que forme parte del caso genérico regulado por alguna regla jurídica) nos encontramos, según Bulygin, con una laguna normativa. Una laguna normativa es un caso en relación con el cual, de acuerdo con él, el derecho no dispone nada. Eugenio Bulygin no distingue entre calificaciones normativas prima facie y calificaciones normativas concluyentes, porque, a su juicio, no hay más calificaciones normativas en el derecho que aquellas que vienen contenidas en reglas predispuestas. Pero si distinguimos entre las reglas y los principios que constituyen sus razones subyacentes, debemos distinguir entre calificaciones normativas prima facie y calificaciones normativas concluyentes. $Y$, desde esta perspectiva, la situación de laguna se producirá si el derecho no dispusiera nada concluyentemente para el caso. Pues bien pudiera suceder que el derecho prima facie no disponga nada, porque el caso no resulte subsumible en ninguna regla predispuesta, pero que sí lo disponga en el nivel de las calificaciones normativas concluyentes, porque así venga exigido por el juego de los principios relevantes. Pues bien: supongamos que el juez se enfrenta a una demanda que

formula una pretensión respecto de la cual el derecho, concluyentemente, no dispone nada. Eugenio Bulygin sostiene que en tal situación el juez tiene tan sólo el deber de fallar

y cumple con él fallando de cualquiera de las maneras posibles. Esta extrañísima tesis, según la cual el juez podría -en el sentido de que le sería permisible- acoger demandas sin respaldo ninguno en el sistema jurídico, viene posibilitada, a mi juicio, porque Bulygin no tiene en cuenta la existencia de una norma que, dictada o no, forma parte, en cuanto que aceptada, por todos los sistemas jurídicos de nuestro horizonte cultural. Tal norma prohíbe al juez acoger demandas sin respaldo en el sistema jurídico y opera como un patrón común y público de decisiones judiciales correctas, de forma que su inobservancia da lugar a críticas que se consideran, sin más, justificadas. ${ }^{9}$

\section{Ocho combinaciones: un cuadro final}

Si combinamos las distinciones entre permisos fuertes y débiles, concluyentes y prima facie, y protegidos y no protegidos, nos encontramos frente al siguiente cuadro de ocho combinaciones posibles: ${ }^{10}$

\begin{tabular}{|c|c|c|c|c|c|c|c|c|}
\hline Tipos de permiso & 1 & 2 & 3 & 4 & 5 & 6 & 7 & 8 \\
\hline fuerte / débil & + & - & + & - & + & - & + & - \\
\hline concluyente / prima facie & + & + & - & - & + & + & - & - \\
\hline
\end{tabular}




\begin{tabular}{|l|l|l|l|l|l|l|l|l|l|}
\hline protegido / no protegido & + & + & + & + & - & - & - & - \\
\hline
\end{tabular}

Ejemplo de la combinación 1 -un permiso fuerte, concluyente y protegido- sería la libertad de información, en un caso en que haya sido considerada prevalente frente a otros principios eventualmente concurrentes.

La combinación 2 -un permiso débil, concluyente y protegido- constituye una imposibilidad conceptual: un permiso débil puede ser concluyente, pero no puede ser un permiso protegido; pues la formulación de la prohibición de interferencia, o de la obligación de facilitación, es una manera indirecta de formular la permisión, con lo que el permiso protegido es necesariamente un permiso fuerte.

Ejemplo de la combinación 3 -un permiso fuerte, prima facie y protegido- sería la libertad de información, tal como aparece en el art. 20 a) de la Constitución española, esto es, antes de ser ponderada con otros principios que pudieran resultar concurrentes (p. ej., los derechos al honor o a la intimidad).

La combinación 4 -un permiso débil, prima facie y protegido- constituye una imposibilidad conceptual por la misma razón por la que lo constituía la combinación 2: un permiso protegido no puede ser un permiso débil, porque la formulación de la obligación de facilitación o de la prohibición de interferencia constituyen otras tantas maneras de formulación indirecta de la permisión.

Ejemplo de la combinación 5 -un permiso fuerte, concluyente y no protegido- sería la libertad de circulación por el territorio nacional, no desplazada por otro principio eventualmente concurrente (por ejemplo, la protección de la salud pública en caso de epidemia) en su vertiente de privilege hohfeldiano, cuyo correlato es el no-derecho de los demás a exigir a su titular que efectúe o no efectúe un cierto desplazamiento. ${ }^{11}$

Ejemplo de la combinación 6 -un permiso débil, concluyente y no protegido- sería el permiso, del que he hecho uso esta mañana, cuando no concurría ninguna norma de la que se pudiera derivar otra calificación normativa para esa acción, de ingerir o no ingerir zumo de naranja.

Ejemplo de la combinación 7 -un permiso fuerte, prima facie y no protegido- sería la libertad de circulación por el territorio nacional, en su vertiente de privilege hohfeldiano, tal como aparece en el art. 19 de la Constitución española, esto es, antes de ser ponderada con otros principios eventualmente concurrentes.

19 Ejemplo de la combinación 8 -un permiso débil,prima facie

y no protegido- sería el permiso como tal de ingerir o no ingerir zumo de naranja, esto es, antes de determinar si concurre alguna norma de la que se pudiera derivar otra calificación normativa para esa acción.

\section{BIBLIOGRAFÍA}

Carlos E. ALCHOURRÓN \& Eugenio BULYGIN, 1971: Normative Systems. Vienna: Springer. 
Carlos E. ALCHOURRÓN \& Eugenio BULYGIN, 1974: Introducción a la metodología de las ciencias jurídicas y sociales. Buenos Aires: Astrea.

Carlos E. ALCHOURRÓN \& Eugenio BULYGIN, 1991a: Permisos y normas permisivas (1984). En: A nálisis lógico y derecho. Madrid: Centro de estudios constitucionales. 215 ss. (Republicado en inglés: Eugenio Bulygin, Permissory Norms and Normative Systems. Essays in Legal Philosophy. Oxford: Oxford University Press, 2015. 324 ss.)

Carlos E. ALCHOURRÓN \& Eugenio BULYGIN, 1991b: Libertad y autoridad normativa (1985). En: A nálisis lógico y derecho. Madrid: Centro de estudios constitucionales. 239 ss.

Manuel ATIENZA \& Juan RUIZ MANERO, 1996: Las piezas del derecho. Teoría de los enunciados jurídicos. Barcelona: Ariel.

Manuel ATIENZA \& Juan RUIZ MANERO, 2000: Ilícitos atípicos. Sobre el abuso del derecho, el fraude de ley y la desviación de poder. Madrid: Trotta.

Juan Carlos BAYÓN, 2009: Sobre el principio de prohibición y las condiciones de verdad de las proposiciones normativas. En E. Bulygin, M. Atienza y J. C. Bayón, 2009: Problemas lógicos en la teoría y la práctica del derecho. Madrid: Fundación Coloquio Jurídico Europeo. 27 ss.

Eugenio BULYGIN, 2005a: Creación y aplicación del derecho. En F. Atria et al., 2005: Lagunas en el derecho. Una controversia sobre el derecho y la función judicial. Madrid-Barcelona: Marcial Pons. 29 ss. Eugenio BULYGIN, 2005b: En defensa de El Dorado. Respuesta a Fernando Atria. En F. Atria et al., 2005: Lagunas en el derecho. Una controversia sobre el derecho y la función judicial. Madrid-Barcelona: Marcial Pons. 73 ss.

Eugenio BULYGIN, 2009a: La importancia de la distinción entre normas y proposiciones normativas. En E. Bulygin, M. Atienza y J. C. Bayón, 2009: Problemas lógicos en la teoría y la práctica del derecho. Madrid: Fundación Coloquio Jurídico Europeo. 9 ss.

Eugenio BULYGIN, 2009b: Creación judicial del derecho. En E. Bulygin, M. Atienza y J. C. Bayón, 2009: Problemas lógicos en la teoría y la práctica del derecho. Madrid: Fundación Coloquio Jurídico Europeo. 75 ss.

Eugenio BULYGIN, 2010: Sobre la equivalencia pragmática entre permiso y no prohibición. Doxa. Cuadernos de filosofía del derecho (2010) 33: 283-296.

Delia Teresa ECHAVE, María Eugenia URQUIJO y Ricardo GUIBOURG, 1980: Lógica, proposición y norma. Buenos Aires: Astrea.

Wesley N. HOHFELD, 1991 [1919]: Conceptos jurídicos fundamentales. México: Fontamara.

Ángeles RÓDENAS, 1998: Entre la transparencia y la opacidad. Análisis del papel de las reglas en el razonamiento judicial. Doxa. Cuadernos de filosofía del derecho (1998) 21/I.

Juan RUIZ MANERO, 2005: Algunas concepciones del derecho y sus lagunas", en F. Atria et al., 2005: Lagunas en el derecho. Una controversia sobre el derecho y la función judicial. Madrid-Barcelona: Marcial Pons. 103 ss.

Juan RUIZ MANERO, 2010: Seguimos discutiendo sobre permisos y concepciones del derecho. Doxa. Cuadernos de filosofía del derecho (2010) 33. 297 ss. 


\section{NOTAS}

1. Una enumeración no exhaustiva de los trabajos de Bulygin en torno a las permisiones sería la siguiente: Alchourrón \& Bulygin 1974, 1991a y 1991b; Bulygin 2005a, 2005b, 2009a, 2009b y 2010. 2. En este sentido, cfr. Bayón 2009 y Ruiz Manero 2010.

3. Cfr. Ruiz Manero 2005 y 2010.

4. Echave, Urquijo y Guibourg 1980: 155-156.

5. Atienza y Ruiz Manero 1996: 105 ss.

6. Sobre este punto ha insistido repetidamente, a mi juicio con entera razón, Eugenio Bulygin. Cfr., por ejemplo, Alchourrón y Bulygin 1991b: 236-237.

7. Cfr. Hohfeld 1991.

8. Sobre los conceptos de «fuera del alcance» y de «excepción», cfr. Ródenas 1998. Sobre estos mismos conceptos, el de «tolerancia jurídica» y, en general, sobre la licitud atípica, cfr. Atienza y Ruiz Manero 2000: cáp. V.

9. En relación con ello, cfr. los textos de Bayón (2009) y Ruiz Manero (2010).

10. El signo (+) indica permiso fuerte, permiso concluyente o permiso protegido; el signo (-) indica las correspondientes clases complementarias (permiso débil, permiso prima facie o permiso no protegido). La categoría de permiso protegido debe entenderse, en este cuadro, en relación con acciones distintas a las de uso de sus poderes normativos por parte de autoridades subordinadas a aquella que dicta el permiso; en relación con estas últimas acciones, los permisos fuertes se encuentran, eo ipso, protegidos. Por otro lado, que un permiso se encuentre protegido implica que no puede ser un permiso débil, pues la formulación de la prohibición de interferencia, o de la obligación de facilitación, supone -como se indica en el texto- una formulación indirecta de la permisión. El hecho de que las distinciones entre permisos fuertes y débiles y permisos protegidos y no protegidos no sean enteramente independientes, sino parcialmente solapadas, afecta, sin duda, a la pulcritud del cuadro: pues ocasiona que las combinaciones 2 y 4 constituyan, como se advierte asimismo en el texto, otras tantas imposibilidades conceptuales.

11. La libertad de circulación por el territorio es un derecho subjetivo de naturaleza compleja: forman parte de él tanto el claim de no ser interferido en los desplazamientos por el territorio, cuyo correlato es el deber de no interferir por parte de todos los demás, como el privilege de desarrollar unos u otros itinerarios, cuyo correlato es el no-derecho de todos los demás a exigir que se desarrollen o no se desarrollen unos itinerarios $u$ otros.

\section{RESÚMENES}

En este trabajo el autor defiende la necesidad de completar la distinción entre permisos fuertes y débiles con otras dos distinciones: una de ellas relativa también al sistema jurídico -la distinción entre permisos protegidos y permisos no protegidos- y la otra relativa al proceso de aplicación del derecho: la distinción entre permisos prima facie y permisos concluyentes. El trabajo concluye con un cuadro en el que, sobre la base de estas tres distinciones, se recogen ocho combinaciones posibles a distinguir en materia de permisos. 
In this paper the author defends the need to make two further distinctions beyond that one existing between strong and weak permissions. One of them is also related to the legal system the distinction between protected and unprotected permissions - and the other one is related to the process of the application of the law, that is, the distinction between prima facie permissions and conclusive permissions. The paper concludes with a table that, on the basis of these three distinctions, presents eight possible combinations to distinguish between permissions.

\section{ÍNDICE}

Palabras claves: permisos fuertes, permisos débiles, permisos protegidos, permisos no protegidos, permisos prima facie, permisos concluyentes, lagunas normativas

Keywords: strong permissions, weak permissions, protected permissions, unprotected permissions, prima facie permissions, conclusive permissions, normative gaps

\section{AUTOR}

\section{JUAN RUIZ MANERO}

Catedrático de la filosofía del derecho en la Universidad de Alicante

Address: Universidad de Alicante - Ap. de correos, 99 - 03080, Alicante - España

E-mail: juan.ruiz@ua.es 